\title{
PERAN KNOWLEDGE SHARING, LEARNING ORGANIZATION DAN INDIVIDUAL INNOVATION CAPABILITY TERHADAP KINERJA KARYAWAN
}

\author{
Satria Avianda Nurcahyo \\ Tri Wikaningrum \\ Fakultas Ekonomi Universitas Islam Sultan Agung ( UNISSULA) Semarang \\ satriaavianda@std.unissula.ac.id,wika@unissula.ac.id
}

\begin{abstract}
The purpose of this study was to determine the effect of Knowledge Sharing, Learning Organization, and Individual Innovation Capability variables on the improvement of Employee Performance. The data used in this study were primary data in the form of questionnaires totaling 50 respondents of functional functional employees in the Center for Agricultural Technology Study in Central Java. The section consists of instructors, researchers, technicians and librarians. The sampling technique used in this study was purposive sampling. Testing of this study used path analysis and to test the effect of intervening variables used the sobel test. The results showed that (1) knowledge sharing has a positive effect on employee performance,(2) knowledge sharing has a positive effect on individual innovation capability,(3) individual innovation capability has a positive effect on employee performance,(4) learning organization has a positive effect on employee performance,(5) learning organization has a positive effect on individual innovation capability,(6) learning organization has a positive effect on knowledge sharing. In this study, of the 4 variables that have the most influence in relation to one another. Namely the Individual Innovation Capability variable with a beta amount of 0.530 . This shows that the real employees in their hearts need support to explore themselves. Then get the freedom to express new innovations they find and be given training in new technologies. Digital technology and financial support are very important for the growth of innovation so that it can improve performance.
\end{abstract}

Keywords: Knowledge Sharing, Learning Organization, Individual Innovation Capability, Employee Performance

\section{PENDAHULUAN}

Pengembangan SDM dan berbagi pengetahuan (knowledge sharing) merupakan upaya yang perlu dilakukan perusahaan dilingkungan karyawan guna mengembangkan kemampuan dalam menghasilkan dan menciptakan sebuah inovasi (Setiarso, 2017). Tanpa tindakan dan Interaksi dari para karyawanya, perusahaan tidak akan bisa menciptakan pengetahuan yang selanjutnya akan dapat menciptakan perilaku yang inovatif dan bermanfaat bagi perusahaan (Andrawina, 2018). Perusahaan sangat diharapkan untuk memiliki sebuah sistem yang dapat membuat karyawan terus menerus termotivasi belajar dan menambah ilmu baru hal ini sesuai dengan gambaran learning organization yang menggambarkan bahwa learning (pembelajaran) merupakan syarat - syarat kesuksesan terjadinya perubahan pada suatu organisasi (Rose, 2015). Oleh karena itu, learning organization memiliki peran sangat penting dalam menumbuhkan minat karyawan 
untuk mengembangkan dan meningkatkan pengetahuanya. Karyawan tidak akan memiliki motivasi untuk melakukan aktivitas belajar dan menambah pengetahuannya jika organisasi tidak mendorong karyawan dalam mengembangkan pengetahuanya. Selain dukungan dari organisasi, dukungan lain dalam bentuk learning organization yang baik sangatlah penting dalam menentukan keberhasilan karyawan mencapai kemampuan kinerja yang tinggi. Kemudian kemampuan berinovasi serta membentuk kreatifitas akan membantu SDM mengatasi permasalahan yang ada di dalam pekerjaan. Oleh karena itu, untuk menghasilkan dan menciptakan sebuah metode kerja yang lebih efektif dan efisien perlu adanya kemampuan berinovasi yang baik, karena kreatifitas dan inovasi merupakan faktor terpenting dalam dunia bisnis agar tidak menjadi pengikut.

Untuk meningkatkan pengetahuan individu dapat diterapkan melalui budaya knowledge sharing, sehingga individu akan dengan sendirinya terdorong untuk melakukan inovasi. Knowledge sharing berperan aktif dalam meningkatkan ke-mampuan individual innovation capability, karena dalam knowledge sharing inilah membantu SDM untuk melakukan penggunaan ulang dan peremajaan pengetahuan yang ada dalam sebuah organisasi, sehingga secara tidak langsung pada ahirnya kemampuan inovasi SDM akan meningkat. Knowledge sharing dapat mendorong terbentuknya ide baru, gagasan, kreativitas serta pemecahan masalah, sehingga knowledge sharing berdampak positif terhadap individual innovation capability (Aulawi, 2009). Disamping itu menurut penelitian yang dilakukan Aristanto (2017) bahwa adanya pengaruh yang positif dan signifikan kinerja karyawan terhadap individual innovation capability penelitian tersebut sejalan dengan Azadehdel (2015) yang menjelaskan bahwa adanya peningkatan dalam individual innovation capability dalam diri karyawan yang berpengaruh pada peningkatan kinerja karyawan
Penilaian kinerja sangatlah penting dalam sebuah organisasi karena dapat memberikan gambaran akan berbagai kemajuan dan perubahan yang telah dicapai (Mankunegara, 2011). Karena kinerja merupakan hasil yang telah dicapai oleh karyawan dalam melaksanakan tanggung jawabnya baik secara kualitas dan kuantitas, disampingituperusahaanjugamenggunakan kinerja karyawan sebagai tolak ukur yang digunakan dalam perencanaan strategi kedepan yang tepat agar dapat bertahan dan bersaing dengan perusahaan lain. Beberapa penelitian terdahulu yang telah dilakukan oleh Andria Trisyulianti (2011), Kuzu (2014), Zaid (2012) dan Obeidat Abdallah (2017) yang menyatakan bahwa adanya pengaruh yang signifikan terhadap knowledge sharing dan kinerja karyawan. Dan terdapat perbedaan penelitian oleh Wahyuni dan Kristiyanto (2013) yang menarik untuk dipelajari lebih lanjut karena mereka mengungkapkan bahwa variabel knowledge sharing tidak memiliki pengaruh signifikan terhadap kinerja karyawan. Penelitian yang dilakukan Nurwanti (2013), Joo (2011) dan Athoilah (2017) mengungkapkan hasil berupa pentingnya variabel learning organization karena memiliki pengaruh positif dan signifikan secara langsung terhadap kinerja karyawan. Selain berpengaruh pada peningkatan kinerja karyawan learning organization juga berperan untuk menumbuhkan minat berinovasi menghasilkan sesuatu proses yang baru dalam diri karyawan yang pada akhirnya dapat meningkatkan kinerja karyawan. Semakin tinggi proses learning organization yang diterapkan maka karyawan memiliki ruang yang bebas untuk menggali ide untuk menumbuhkan individual innovation capability seperti dalam studi penelitian Fanbasten (2014) pada karyawan PT SIT Global System sebuah perusahaan konsultan IT di negara Swedia menunjukkan hasil adanya pengaruh positif dan signifikan antara learning organization dan individual innovation capability. Hal ini menunjukkan 
bahwa semakin tinggi perusahaan dalam meningkatkan volume dan kapasitas pembelajaran bagi karyawan maka makin bertambah tingginya minat karyawan untuk menciptakan sebuah proses inovasi pembaruan dalam perusahaan. Selain itu hal yang sama juga diungkapkan oleh Li-An Ho (2010) bahwa adanya hasil yang positif dan signifikan antara learning organization dan individual innovation capability pada 15 perusahaan teknologi dengan sampel 412 karyawan di negara Taiwan. Menurut data Badan Pusat Statistik (BPS) 2017, penduduk Indonesia paling banyak bekerja di sektor pertanian, di sektor ini sedikitnya ada 39,68 juta orang yang bekerja, atau $31,86 \%$ dari total penduduk bekerja oleh karena itu departemen pertanian Indonesia sebagai jembatan antara pemerintah dan petani memerlukan SDM yang mampu meningkatkan kinerjanya demi mendukung ketahanan pangan negara Indonesia dilihat dari data produktivitas padi dalam lima tahun trakhir di pulau Jawa, Jawa Tengah termasuk dalam kategori yang paling rendah diantara dua provinsiyang lain. Terhitung Jawa Tengah hanya mampu mencapai angka 57,51\% produktivitas padi dibawah Jawa Barat dan Jawa Timur. Berdasarkan fenomena tersebut perlu adanya pengembangan SDM Balai Pengkajian Teknologi Pertanian Jawa Tengah untuk meningkatkan kinerja yaitu melalui konsep peran knowledge sharing, learning organization dan penumbuhan individual innovation capability.

\section{KAJIAN LITERATUR Knowledge Sharing}

$\begin{array}{lcr}\begin{array}{c}\text { Menurut } \\ \text { Leranggapan }\end{array} \begin{array}{c}\text { bahtobing } \\ \text { bahwa }\end{array} & \begin{array}{r}\text { (2011) } \\ \text { sebuah } \\ \text { dalam }\end{array} \\ \text { rangkaian yang sistematis } & \begin{array}{c}\text { dalan } \\ \text { mentransfer,mendistribusikan pengetahuan }\end{array} \\ \text { kepada seseorang dan organisasi melalui } \\ \text { berbagai media yang variatif. Kemudian } \\ \text { menurut Tobing Paul (2007) mendefinisikan } \\ \text { knowledge sharing dibagi menjadi dua jenis, } \\ \text { yaitu tacit knowledge dan explicit knowledge. } \\ \text { Dalam tacit knowledge meliputi sesuatu }\end{array}$

yang ada di dalam diri manusia yang dimiliki sejak lahir dan berbeda diantara satu dan yang lain, di benak manusia yang berbentuk intuisi,dan juga judgement skill,value dan belief yang tidak bisa ditiru oleh orang lain,dan juga tacit knowledge diartikan sebagai pengetahuan secara individu atau perorangan melalui pengalaman yang dilalui dengan situasi dan kondisi yang berbeda- beda dalam memnbentuk sebuah pengetahuan baru.

Sedangkan explicit knowledge dapat diartikan sesuatu yang bersifat formal dan mudah diterima dan mudah didistribusikan lewat media serta mudah untuk dikomunikasikan dan dibagikan kepada orang lain dalam bentuk sesuatu yang baru (Noviyanti, 2015). Namun penerapan explicit knowledge lebih mudah diterima karena pengetahuan dinyatakan dalam bentuk tulisan tau pernyataan yang didokumentasikan, sehingga tiap individu bisa mempelajarinya secara mandiri. Jadi jika disimpulkan secara umum knowledge sharing merupakan rangkaian proses pembelajaran secara bersama-sama dengan berbagi pengetahuan antar karyawan yang melibatkan individu yang satu dengann individu yang lain dengan melibatkan pengalaman yang dapat dijadikan sumber dalam berbagi pengetahuan. Indikator yang ada dalam knowledge sharing menurut Chuang (2013) yaitu Kesediaan berbagi pengetahuan khusus, Kesediaan berbagi pengetahuan secara virtual, Kesediaan memberi saran dalam pekerjaan, Kesediaan berdiskusi selama pertemuan dan Kesediaan berbagi pengalaman sebagai solusi

\section{Learning Organization}

Learning organization dalah sebuah pola proses tata perilaku organisasi yang berproses dan terus menerus menumbuhkan kemauanya serta memiliki tujuan untuk merubah kapasitasnya sehingga dapat tercapainya tujuan organisasi (Marsicks, Watkins, 2015). Learning organization menurut Garvin (2019) merupakan sebuah 
kemampuan skill dan keahlian sebuah organisasi untuk membentuk, menggapai, menginterprestasikan atau menafsirkan dan menstransfer ilmu pengetahuan yang ada dalam individu dan organiasi yang bertujuan memodifikasi pelaku untuk dapat menggambarkan pengetahuan yang baru dan belum pernah ada sebelumnya. Kemudian indikator learning organization menurut (Marsicks, Watkins, 2015) yaitu meliputi Adanya dorongan memahami keahlian,Adanya dorongan untuk belajar dan membantu, Dorongan perusahaan untuk melakukan pembelajaran, Adanya umpan balik adil dan terbuka,Adanya diskusi lintas jabatan serta Adanya penghargaan atas pembelajaran

\section{Individual Innovation Capability}

Usswanitchakit (2007), mengartikan individual innovation capability sebagai kemampuan untuk mengembangkan sesuatu hal yang baru yang belum ada sebelumnya dengan menerapkan prosesproses teknologi yang lebih tepat dalam mengembangkan Sesuatu hal yang baru agar tidak pula dilakukan oleh pesaing. Sedangkan menurut Aulawi (2009) individual innovation capablility dapat diartikan sebagai pola karakteristik kepribadian yang mengukur kesediaan individu untuk berubah, kemudian pola prespektif perilaku yang berfokus pada penegmbangan ide - ide yang langka yang diaktualisasikan melalui perilaku dan pola prespektif output yaitu didasarkan hasil akhir individu dalam menghasilkan sesuatu yang baru. Jadi dapat disimpulkan bahwa individual innovation capability adalah serangkaian prosese penemuan hal baru yang belum ada sebelumnya melalui pola kepribadian,perilaku dan hasil akhir guna mengembangkan suatu hal yang tidak dapat dilakukan oleh pesaing.

Indikator individual innovation capability menurut Jong (2007) meliputi Kesediaan individuuntukberubah,Kemampuanmencoba hal baru, Kemampuan menghasilkan proses baru

\section{Kinerja Karyawan}

Kinerja Karyawan adalah hasil melakukan sebuah pekerjaan secara nyata dan dapat dilihat kualitas dan kuantitas yang telah dicapai oleh karyawan dalam melaksanakan tugas dan tanggung jawab yang telah dibebankan kepadanya. (Mankunegara, 2011). Pengertian lain yaitu Kinerja Karyawan adalah hasil perolehan kerja seseorang secara akumulatif selama kurun waktu periode tertentu di dalam melaksanakan tugas dan tanggung jawabnya untuk memenuhi target sasaran kerja yang telah disepakati bersama sama (Rivai, 2005). Kemudian Kinerja Karyawan juga dapat diartikan sebagai sebuah output akhir yang dapat dicapai oleh individu atau kelompok dan organisasi dari segi kuantitatif dan kualitatif sesuai porsi dan tugas masing masing dalam pencapaian tujuan yang ada dalam organisasi secara sah dan tidak melanggar hukum (Moeheriono, 2009). Kemudian indikator yang dapat digunakan untuk mengukur kinerja karyawan Ana Suzete (2016) yaitu meliputi kualitas kerja, kuantitas kerja, adaptabilitas dan fleksibilitas yang dimiliki oleh karyawan.

\section{Hubungan Antara Knowledge Sharing dan Kinerja Karyawan}

Hasil penelitian yang dilakukan oleh Kuzu \& Ozilham (2014) menjelaskan adanya pengaruh yang positif dan signifikan knowledge sharing untuk meningkatkan kinerja karyawan industri servis telekomunikasi di Jerman, Andria,Trisyulianti (2011) juga menjelaskan adanya pengaruh yang positif dan signifikan knowledge sharing untuk meningkatkan kinerja karyawan di PT Telekomunikasi Indoneisa Tbk, Obeidat Abdallah (2017) juga mengungkapkan adanya pengaruh yang positif dan signifikan knowledge sharing untuk meningkatkan kinerja pada 356 karyawan manufaktur di negara Jordania. Hal ini menunjukkan bahwa adanya pengaruh positif dan signifikan knowledge sahring terhadap kinerja karyawan, menurut mereka semakin 
tinggi kesempatan yang diberikan atasan dalam karyawan menyampaikan ide, kritik serta pendapat dan komentarnya padarekan kerja maka akan semakin meningkatkan kinerja.

\section{Hubungan Antara Knowledge Sharing dan Individual Innovation Capability}

Dalam studi penelitian yang dilakukan oleh Aulawi Hilmi (2009) mengungkapkan adanya pengaruh yang signifikan dan positif antara knowledge sharing dan individual innovation capability, menurutnya karena knowledge sharing dapat memberikan fasilitator bagi para karyawan untuk meregenerasi pengetahuan yang baru yang ada dalam organisasi sehingga kemampuan inovasi individu dalam organisasi akan meningkat. Kemudian dalam penelitian yang lain yang dilakukan oleh Aristanto (2017) menyatakan bahwa knowledge sharing juga memiliki pengaruh yang positif dan signifikan terhadap individual innovation capability dan sejalan dengan penelitian Zohoori (2013) yang mengungkapkan bahwa meningkatnya aktivitas knowledge sharing yang dilakukan oleh karyawan akan berpengaruh pada meningkatnya individual innovation capability karyawan.

\section{Hubungan Antara Individual Innovation Capability dan Kinerja Karyawan}

Dalam studi yang dilakukan Novian (2013) mengungkapkan adanya pengaruh yang postif dan signifikan antara individual innovation capaility terhadap kinerja karyawan. Hal ini mendukung penelitian yang dilakukan oleh Aristanto (2017) yang menyatakan bahwa kinerja karyawan berpengaruh positif dan signifikan terhadap individual innovation capability kemudian Azadehdel (2013) juga mengungkapkan peningkatan individual innovation capability berpengaruh pada peningkatan kinerja karyawan dan menyatakan bahwa kemampuan inovasi dalam individu akan meningkatkan dan menghasilkan sesuatu yang baru pada peningkatan kinerja karyawan.

\section{Hubungan Antara Learning Organization dan Kinerja Karyawan}

Dalam studi yang telah dilakukan oleh Joo (2011) menjelaskan adanya pengaruh yang positifdan signifikan learning organization dan kinerja karyawan pada 452 pekerja manufaktur di negara Korea. Rose (2011) juga menjelaskan adanya pengaruh yang positifdan signifikan learning organization dan kinerja karyawan sektor publik negara Malaysia, Nurwanti (2013) juga menjelaskan bahwa learning oeganization berpengaruh positif dan signifikan terhadap kinerja karyawan hal itu dikarenakan adanya kesadaran perusahaan untuk melakukan peningkatan kapasitas pembelajaran karyawan seperti atasan yang terjun langsung dalam dalam diskusi tim, bertanggung jawab, mempermudah bantuan untuk tim dan berusaha berlaku adil dengan baik maka akan meningkatkan potensi kinerja karyawan. Selain itu hal yang sama juga diungkapkan oleh Cinthya (2018) bahwa learning organization berpengaruh positif dan signifikan terhadap kinerja. Bahwa semakin tinggi kemampuan perusahaan atau organisasi dalam meningkatkan kapasitas pembelajaran karyawan maka akan berpengaruh pula pada tingginya kinerja karyawan .

\section{Hubungan Antara Learning Organization dan Individual Innovation Capability}

Dalam Studi penelitian Fanbasten (2014) pada karyawan PT SIT Global System sebuah perusahaan konsultan IT di negara Swedia menunjukkan hasil adanya pengaruh positifdan signifikan antara learning organization dan individual innovation capability. Hal ini menunjukkan bahwa semakin tinggi perusahaan dalam meningkatkan volume dan kapasitas pembelajaran bagi karyawan maka makin bertambah tingginya minat karyawan untuk menciptakan sebuah proses inovasi pembaruan dalam perusahaan. Selain itu hal yang sama juga diungkapkan oleh Li-An Ho (2010) bahwa adanya hasil yang positif 


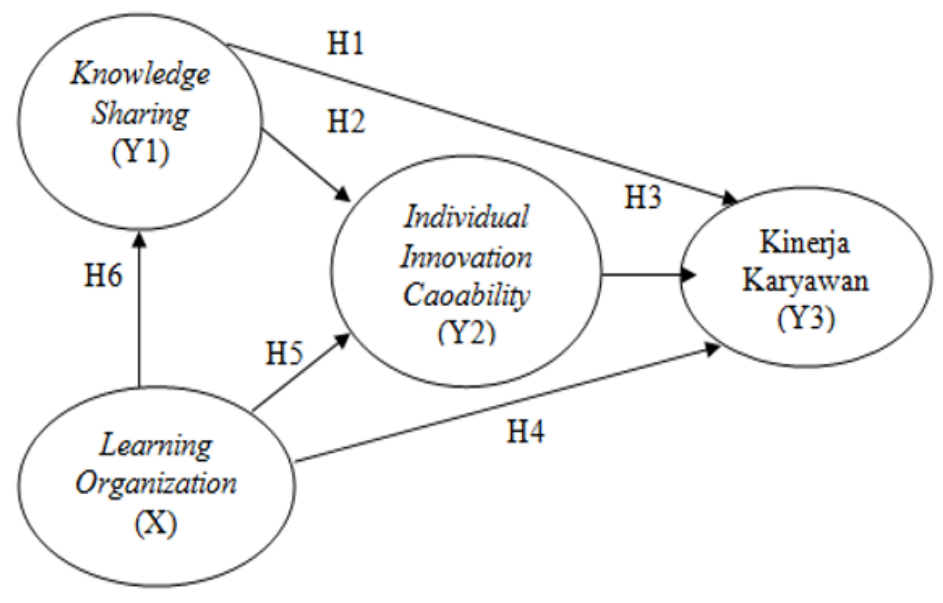

Gambar 1.1

Model Penelitian

dan signifikan antara learning organization dan individual innovation capability pada 15 perusahaan teknologi dengan sampel 412 karyawan di negara Taiwan. Mehmet (2015) juga menjelaskan hal yang sama pada penelitianya di sektor perbankan negara Turkey bahwa adanya pengaruh yang positif dan signifikan antara learning organization dan individual innovation capability

\section{Hubungan Antara Learning Organization dan Knowledge Sharing}

Dalam Studi penelitian yang dilakukan oleh Athoilah (2017) menunjukkan hasil yang signifkan bahwa adanya pengaruh positif antara learning organization dan knowledge sharing pada karyawan asurasi Prudential Life. Hal ini menunjukkan bahwa semakin tinngi perusahaan dalam meningkatkan volume dan kapasitas pembelajaran bagi karyawan maka semakin menambah tingginya minat karyawan untuk saling berbagi pengetahuan dan membentuk pengetahuan yang baru. Selain itu hal yang sama juga diungkapkan oleh Joo (2011) hasil yang signifkan bahwa adanya pengaruh positif antara learning organization dan knowledge sharing pada 452 karyawan manufaktur negara Korea. Nurwanti (2013) juga menjelaskan hasil yang signifkan bahwa adanya pengaruh positif antara learning organization dan knowledge sharing pada staff akademisi perguruan tinggi swasta di Jakarta. Rose (2011) juga menjelaskan bahwa adanya pengaruh positif antara learning organization dan knowledge sharing pada karyawan sektor publik negara Malaysia dan Makrufah (2011) dalam penelitianya menjelaskan bahwa learning oeganization berpengaruh positif dan signifikan terhadap knowledge sharing dan kinerja karyawan Hotel Bumi Surabaya.

\section{POPULASI DAN SAMPEL}

Dalam penelitian ini populasinya adalah karyawan fungsional khusus karena bagian fungsional khusus cocok dan tepat menginterprestasikan variabel penelitian. Dikarenakan mereka bekerja tidak terbatasi SOP,namun secara bebas mengumpukan angka kredit point untuk kenaikan pangkat. Fungsional khusus BPTP Jawa Tengah yang terdiri dari peneliti, penyuluh, teknik litkayasa dan pustakawan yang berjumlah 99 orang. Teknik penarikan sampel yang digunakan dalam penelitian ini adalah teknik purposive sampling dimana cara penarikan sampel dalam memilih subjek berdasarkan kriteria yang telah peneliti tentukan berdasarkan tujuan penelitian. Kriterianya adalah karyawan tetap, yang memiliki masa kerja minimal satu tahun 
dan karyawan yang mengumpulkan kredit point untuk kenaikan pangkat sebagai aparatur sipil negara (fungsional khusus). Jadi berdasarkan hasil perhitungan rumus Slovin, maka jumlah sampel minimal yang perlu diambil dalam penelitian ini adalah karyawan bagian fungsional khusus BPTP Jawa Tengah sebesar 50 responden.

\section{HASIL DAN PEMBAHASAN Hasil Penelitian}

Dari hasil uji validitas variabel Knowledge Sharing, Learning Organization ,Individual Innovation Capability, dan Kinerja Karyawan dapat dikatakan bahwa keseluruhan indikator yang diajukan oleh peneliti terhadap responden valid. Pengujian validitas ini digunakan untuk mengukur sah atau valid tidaknya sutau indikator yang mewakili variabel. Indikator dalam penelitian ini dapat mewakili variabel sehingga menghasilkan nilai $r$ hitung $>r$ tabel. Serta, variabel Knowledge Sharing, Learning Organization ,Individual Innovation Capability,dan Kinerja Karyawan telah memenuhi persyaratan, artinya bahwa variabel memiliki nilai alpha diatas 0,60 sehingga keseluruhan variabel adalah reliabel. pengukur di dalam mengukur gejala yang sama

\section{Pengaruh Learning Organization terhadap Knowledge Sharing}

Berdasarkan dari hasil penelitian yang diperoleh nilai dari koefisien Learning Organization sebesar 0,452 dengan nilai probabilitasnya 0,001 lebih kecil dari level signifikan yang digunakan sebesar 0,05 yang memiliki arti hipotesis nol $(\mathrm{HO})$ ditolak dan hipotesis alternatif $(\mathrm{Ha})$ diterima. Dengan hasil tersebut maka Learning Organization berpengaruh positif dan signifikan terhadap Knowledge Sharing. Pengujian tersebut mampu menerima hipotesis pertama, sehingga dugaan yang menyatakan Learning Organization berpengaruh positif terhadap Knowledge Sharing diterima.
Dari hasil pertanyaan terbuka kuesioner dibagi dalam berbagai kelompok untuk melakukan penyuluhan program pertanian dari pemerintah agar masuk desa, untuk melakukan hal tersebut karyawan pastilah menggunakan konsep knowledge sharing saling tukar ilmu pada yang lebih senior atau bidangnya agar tidak salah dalam memberikan penyuluhan, dikarenakan pengalaman petani desa lebih dikatakan sangat baik. Kemudian pula saat dilakukan uji kompoisisi baru tanaman pangan pastilah disamping organisasi yang pembelajar masih membutuhkan berbagi pengetahuan dengan orang orang yang sudah lama berkecimpung di bidang tersebut

\section{Pengaruh Knowledge Sharing Terhadap Individual Innovation Capability}

Berdasarkan dari hasil penelitian yang diperoleh nilai dari koefisien Knowldge Sharing sebesar 0,285 dengan nilai probabilitasnya 0,013 lebih kecil dari level signifikan yang digunakan sebesar 0,05 yang memiliki arti hipotesis nol $(\mathrm{HO})$ ditolak dan hipotesis alternatif $(\mathrm{Ha})$ diterima. Dengan hasil tersebut maka Knowledge Sharing berpengaruh positif dan signifikan terhadap Individual Innovation Capability. Pengujian tersebut mampu menerima hipotesis kedua, sehingga dugaan yang menyatakan Knowledge Sharing berpengaruh positif terhadap Individual Innovation Capability diterima. Dari hasil pertanyaan terbuka dijelaskan bahwa pada saat karyawan mendapat cerita pengalaman dari senior mereka, timbul minat untuk mencoba hal baru tersebut dengan dibuktikan dengan nilai kesediaan mereka untuk berubah yang tergolong sangat tinggi. Knowledge Sharing ini memantik minat dalam diri karyawan untuk mengimprovisasikan serta mengembangkan kemampuan individual mereka melalui hal hal baru yang bersumber dari aktivitas berbagi dalam knowledge sharing. 


\section{Pengaruh Learning Organization terhadap Individual Innovation Capability}

Berdasarkan dari hasil penelitian yang diperoleh nilai dari koefisien Learning Organization sebesar 0,274 dengan nilai probabilitasnya 0,042 lebih kecil dari level signifikan yang digunakan sebesar 0,05 yang memiliki arti hipotesis nol $(\mathrm{H} 0)$ ditolak dan hipotesis alternatif ( $\mathrm{Ha}$ ) diterima. Dengan hasil tersebut maka Learning Organization berpengaruh positif dan signifikan terhadap Individual Innovation Capability. Pengujian tersebut mampu menerima hipotesis ketiga, sehingga dugaan yang menyatakan Learning Organization berpengaruh positif terhadap Individual Innovation Capability diterima. Dari hasil pertanyaan terbuka kuesioner disampaikan bahwa untuk mencapai target pekerjaan sudah ada SKP (Sasaran Kinerja Pegawai). SKP inilah yang menjadi tolak unkur prestasi inovasi yang dihasilkan karyawan. Untuk menghasilkan sebuah inovasi dibutuhkan kerjasama saling belajar dalam setiap lini manajemen,saling bertukar ide dan timbulah persaingan dan berlomba menaikkan angka kredit yang berguna sebagai syarat kenaikan pangkat golongan pada aparatur sipil negara yang akan menyebabkan inovasi tumbuh. Kemudian dari indikator Learning Organization berupa adanya diskusi lintas lini dapat mendukung munculnya ide - ide inovasi baru dari berbagai posisi karyawan yang berbeda.

\section{Pengaruh Knowledge Sharing Terhadap Kinerja Karyawan}

Berdasarkan dari hasil penelitian yang diperoleh nilai dari koefisien Knowldge Sharing sebesar 0,102 dengan nilai probabilitasnya 0,025 lebih kecil dari level signifikan yang digunakan sebesar 0,05 yang memiliki arti hipotesis nol $(\mathrm{HO})$ ditolak dan hipotesis alternatif $(\mathrm{Ha})$ diterima. Dengan hasil tersebut maka Knowledge Sharing berpengaruh positif dan signifikan terhadap Kinerja Karyawan. Pengujian tersebut mampu menerima hipotesis keempat, sehingga dugaan yang menyatakan Knowledge Sharing berpengaruh positif terhadap Kinerja Karyawan diterima. Dari hasil pertanyaan terbuka dijelaskan bahwa mereka sangat sukarela berbagi pengetahuan dengan cara informal melalui perbincangan sehari hari dan formal melalui seminar internal. Kemudian dilakukan pula pengkaderan dari senior ke yunior, memberikan ajakan kepada karyawan lain yang berbeda displin ilmu dalam suatu kegiatan expo,serta melakukan penelitian ilmiah secara team untuk meningkatkan kinerja SDM dalam mengejar kredit point untuk kenaikan pangkat dan golongan.

\section{Pengaruh Individual Innovation Capability Terhadap Kinerja Karyawan}

Berdasarkan dari hasil penelitian yang diperoleh nilai dari koefisien Knowldge Sharing sebesar 0,530 dengan nilai probabilitasnya 0,000 lebih kecil dari level signifikan yang digunakan sebesar 0,05 yang memiliki arti hipotesis nol $(\mathrm{HO})$ ditolak dan hipotesis alternatif $(\mathrm{Ha})$ diterima. Dengan hasil tersebut maka Individual Innovation Capability berpengaruh positif dan signifikan terhadap Kinerja Karyawan. Pengujian tersebut mampu menerima hipotesis kelima, sehingga dugaan yang menyatakan Individual Innovation Capability berpengaruh positif terhadap Kinerja Karyawan diterima. Dilihat dari pertanyaan terbuka kuesioner yaitu karyawan diberikan kebebasan berinovasi menemukan formula baru serta diberi kebebasan mengeksploitasi sesuatu yang belum ditemukan sebelumnya lewat praktek- praktek percobaan diberbagai bidang. Sehingga mendorong adanya pembaharuan dalam pertanian di era millenial petani sudah tidak identik dengan mencangkul namun lewat teknologi teknologi baru. Contohnya diterapkan program kloning bibit unggul,persilangan bibit unggul dan pematian bibit untuk diekspor keluar negri agar tidak dijiplak hal ini direspon karyawan mereka menyatakan target pekerjaan akan lebih menyenagkan jika diberi kesempatan 
berinovasi yang tinggi.

\section{Pengaruh Learning Organization terhadap Kinerja Karyawan}

Berdasarkan dari hasil penelitian yang diperoleh nilai dari koefisien Learning Organization sebesar 0,341 dengan nilai probabilitasnya 0,009 lebih kecil dari level signifikan yang digunakan sebesar 0,05 yang memiliki arti hipotesis nol $(\mathrm{HO})$ ditolak dan hipotesis alternatif $(\mathrm{Ha})$ diterima. Dengan hasil tersebut maka Learning Organization berpengaruh positif dan signifikan terhadap Kinerja Karyawan. Pengujian tersebut mampu menerima hipotesis pertama, sehingga dugaan yang menyatakan Learning Organization berpengaruh positif terhadap Kinerja Karyawan diterima. Dari hasil pertanyaan terbuka dengan cara mengikutkan karyawan dalam berbagai pelatihan, ada target nominal nilai dalam kuantitas menghasilkan karya ilmiahserta mengikuti seminar/workshop yang bertujuan mengumpulkan point untuk kenaikan pangkat, sehingga mau tidak mau mereka akan terpacu untuk meningkatkan point dalam kinerja mereka. Hal ini menunjukkan bahwasituasiuntukmelakukan pembelajaran dan adanya dorongan dari kantor begitu terbuka dan berjalan. Sehingga, karyawan yang akan mengumpulkan kredit point untuk memenuhi SKP (Sasaran Kinerja Pegawai) sangat terbantu akan hal ini sehingga dapat meningkatkan kinerja mereka.

\section{Hasil Uji Sobel Pengaruh Knowledge Sharing Terhadap Kinerja Karyawan melalui Individual Innovation Capability}

Berdasarkan perhitungan diatas diperoleh sobel test statistic sebesar 2,391. jika nilai sobel test lebih besar dari pada nilai tabel z (0.05) atau 1.96 maka dapat disimpulkan ada pengaruh tidak langsung pada model regresi. Jadi pada sobel test 2,391 >1.96 ada pengaruh tidak langsung antara Knowledge Sharing terhadap Kinerja karyawan melalui Individual Innovation Capability.Pengujian tersebut dapat diartikan bahwa Individual Innovation Capability mampu menjadi variabel intervening antara Knowledge Sharing terhadap Kinerja Karyawan. Artinya dengan adanya kapabilitas individu untuk berinovasi akan mempengaruhi minat menemukan sesuatu yang baru sehingga pada saat berbagi pengetahuan antar karyawan yang dapat meningkatkan kinerja mereka. Jadi jiwa menemukan sesuatu yang baru dalam diri karyawan akan tumbuh seiring banyaknya waktu karyawan bertukar pikiran dengan karyawan lain. Sehingga inspirasi dan minat daya saing dalam diri karyawan akan tumbuh sehingga timbulah daya saing yang positif dalam meningkatkan kinerja karyawan.

\section{Hasil Uji Sobel Pengaruh Learning Organization Terhadap Kinerja Karyawan melalui Individual Innovation Capability \\ Berdasarkan perhitungan diatas} diperoleh sobel test statistic sebesar 2,047. jika nilai sobel test lebih besar dari pada nilai tabel z (0.05) atau 1.96 maka dapat disimpulkan ada pengaruh tidak langsung pada model regresi. Jadi pada sobel test $2,047>1.96$ ada pengaruh tidak langsung antara Learning Organization terhadap Kinerja karyawan melalui Individual Innovation Capability. Pengujian tersebut dapat diartikan bahwa Individual Innovation Capability mampu menjadi variabel intervening antara Learning Organization terhadap Kinerja Karyawan. Artinya dengan adanya kapabilitas individu untuk berinovasi akan mempengaruhi minat menemukan sesuatu yang baru sehingga akan dilakukan proses belajar secara bersama - sama. Organisasi pembelajar bersama sama menumbuhkan kemauanya untuk belajar demi mencapai tujuan organisasi. Sehingga dalam diri antar karyawan dapat tumbuh rasa untuk maju, rasa untuk berkembang mencapai yang dicita-citakan serta rasa ingin menjadi teladan sehingga kinerja akan mereka pacu. 


\section{Hasil Uji Sobel Pengaruh Learning Organization Terhadap Individual Innovation Capability melalui Knowledge Sharing}

Berdasarkan perhitungan diatas diperoleh sobel test statistic sebesar 2,211. jika nilai sobel test lebih besar dari pada nilai tabel $z(0.05)$ atau 1.96 maka dapat disimpulkan ada pengaruh tidak langsung pada model regresi. Jadi pada sobel test 2,211 > 1.96 ada pengaruh tidak langsung antara Learning Organization terhadap Individual Innovation Capability melalui Knowledge Sharing. Pengujian tersebut dapat diartikan bahwa Knowledge Sharing mampu menjadi variabel intervening antara Learning Organization terhadap Individual Innovation Capability. Artinya dengan adanya kegiatan berbagi pengetahuan secara sukarela dan terbuka maka organisasi pembelajar akan bersama sama menumbuhkan kemauanya untuk belajar demi mencapai tujuan organisasi dengan cara membentuk kelompok - kelompok belajar yang bertujuan meningkatkan keahlian konsentrasi bidang keilmuan. Sehingga dalam diri antar karyawan dapat tumbuh rasa bersaing dan berlomba untuk menciptakan sebuah inovasi dan penemuan baru yang bermanfaat bagi organisasi.

\section{Hasil Uji Sobel Pengaruh Learning Organization Terhadap Kinerja} Karyawanmelalui Knowledge Sharing

Berdasarkan perhitungan diatas diperoleh sobel test statistic sebesar 2,166. jika nilai sobel test lebih besar dari pada nilai tabel z (0.05) atau 1.96 maka dapat disimpulkan ada pengaruh tidak langsung pada model regresi. Jadi pada sobel test $2,166>1.96$ ada pengaruh tidak langsung antara Learning Organization terhadap Kinerja Karyawan melalui Knowledge Sharing. Pengujian tersebut dapat diartikan bahwa Knowledge Sharing mampu menjadi variabel intervening antara Learning Organization terhadap Kinerja Karyawan. Artinya dengan adanya kegiatan berbagi pengetahuan secara sukarela dan terbuka maka organisasi pembelajar bersama sama menumbuhkan kemauanya untuk belajar demi mencapai tujuan organisasi. Sehingga dalam diri antar karyawan dapat tumbuh rasa untuk maju, rasa untuk berkembang mencapai yang dicita-citakan serta rasa ingin menjadi teladan. Sehingga kinerja akan mereka tingkatkan.

\section{KESIMPULAN}

1. Knowledge Sharing mempunyai pengaruh yang signifikan terhadap Kinerja Karyawan BPTP Jawa Tengah. Hal ini berarti bahwa tingkat Knowledge Sharing yang tinggi memiliki pengaruh yang semakin besar terhadap Kinerja pada karyawan jabatan fungsional khusus.Knowledge Sharing memiliki pengaruh positif signifikan terhadap Individual Innovation Capability. Individual Innovation Capability mempunyai pengaruh yang positif signifikan terhadap peningkatan kinerja karyawan fungsional di BPTP Jawa Tengah. Learning Organization memiliki pengaruh yang positif signifikan terhadap peningkatan kinerja karyawan fungsional BPTP Jawa Tengah. Learning Organization memiliki pengaruh yang positif signifikan terhadap peningkatan Individual Innovation Capability karyawan fungsional BPTP Jawa Tengah. Learning Organization memiliki pengaruh yang positif signifikan terhadap peningkatan Knowledge Sharing karyawan fungsional BPTP Jawa Tengah.

2. Dari hasil sobel test Individual Innovation Capability mampu menjadi variabel intervening anata Knowledge Sharing dan Kinerja Karyawan . Artinya dengan adanya kapabilitas individu untuk berinovasi akan menjadi penghubung yang tidak langsung pada saat berbagi pengetahuan antar karyawan yang dapat meningkatkan kinerja mereka. Dari hasil sobel test Individual Innovation Capability mampu menjadi variabel 
intervening antara Learning Organization dan Kinerja Karyawan . Artinya dengan adanya kapabilitas individu untuk berinovasi akan menjadi penghubung yang tidak langsung pada saat organisasi pembelajar bersama sama menumbuhkan kemauanya untuk belajar demi mencapai tujuan organisasi

Dari hasil sobel test Knowledge Sharing mampu menjadi variabel intervening antara Learning Organization dan Individual Innovation Capability. Artinya dengan adanya kegiatan berbagi pengetahuan secara sukarela dan terbuka maka organisasi pembelajar akan bersama sama menumbuhkan kemauanya untuk belajar demi mencapai tujuan organisasi dengan cara membentuk kelompok - kelompok belajar yang bertujuan meningkatkan keahlian konsentrasi bidang keilmuan.

Dari hasil sobel test Knowledge Sharing mampu menjadi variabel intervening antara Learning Organization dan Kinerja Karyawan. dengan adanya kegiatan berbagi pengetahuan secara sukarela dan terbuka maka organisasi pembelajar bersama sama menumbuhkan kemauanya untuk belajar demi mencapai tujuan organisasi. Sehingga dalam diri antar karyawan dapat tumbuh rasa untuk maju, rasa untuk berkembang mencapai yang dicita-citakan serta rasa ingin menjadi teladan. Sehingga kinerja akan mereka tingkatkan.

\section{IMPLIKASI MANAJERIAL}

1. Keamapuan inovasi dalam diri karyawan merupakan hal mendasar dalam mengeluarkan ide - ide demi kemajuan organisasi. Dalam penelitian ini dari 4 variabel yang memiliki pengaruh paling besar dalam keterkaitanya antara satu dan yang lain. Yaitu variabel Individual Innovation Capability dengan jumlah beta 0,530. Hal ini menunjukkan karyawan sebenarnya dalam lubuk hati mereka yang terdalam membutuhkan dukungan untuk mengeksplor diri mereka. Kemudian memperoleh kebebasan mengungkapkan inovasi baru yang mereka temukan serta diberikan pelatihan akan teknologi baru. Teknologi digital dan dukungan berupa finansial merupakan hal yang sangat penting bagi tumbuhnya inovasi. Inovasi yang dimaksudkan yaitu sebuah penemuan yang dapat mendukung perubahan perkembangan zaman. Sehingga penemuan tersebut dapat mematikan pola pikir anak muda bahwa konsep bertani sudah tidak identik dengan sawah dan cangkul, melainkan sudah moderen dan berkembang. Karena revolusi industri yang terus berkembang ke era digital, kemampuan inovasi dan cakap teknologi dapat mendukung meningkatnya kinerja karyawan BPTP Jawa Tengah.

2. Pembelajaran dalam sebuah organisasi merupakan hal yang mendukung persaudaraan antar karyawan dan menciptakan rasa kekeluargaan karena dalam situasi belajar antar lini inilah kebebasan karyawan bertukar pikiran opini serta pengalaman dapat terlaksana. Adanya diskusi lintas lini sehingga para junior pun mendapat pembelajaran dari seniornya dan perlahan mengikis rasa acuh pada ilmu pengetahuan yang dapat meningkatkan skill dalam pekerjaan. Learning Organization memiliki pengaruh terbesar kedua yaitu dengan tingkat beta 0,452 hal ini mengindikasikan bahwa organisasi pembelajar memiliki pengaruh terbesar kedua dalam penelitian ini yang layak dikaji lebih lanjut. Diharapkan kantor dapat memperluas kegiatan bertukar pengetahuan, pengalaman dan skill tanpa hanya terbatas di sesi diskusi formal saja karena diskusi nonformal juga dapat mempererat rasa saling memiliki organisasi antar karyawan.

\section{PENELITIAN MENDATANG}

1. Penelitian yang akan mendatang harus lebih banyak lagi variabel yang 
digunakan contohnya, knowledge absorption, knowledge management, organizational learning dan knowledge transfer sehingga mampu memperkuat suatu penelitian, permasalahan lebih lengkap dan kemungkinan berdampak pada penemuan teknologi virtual dan digital baru yang dapat meningkatkan kinerja karyawan. Kemudian penelitian mendatang disarankan menambah objek penelitian instansi yang menerapkan teknologi digital seperti perusahaan iklan,perusahaan entertaintmen dan perusahaan dibidang teknologi industri virtual yang menuntut karyawanya bebas melakukan inovasi pembaharuan tanpa terhalang oleh SOP sehingga tumbuhlah ide inovasi segar bagi perusahaan.

\section{DAFTAR PUSTAKA}

Andrawina, Luciana. (2018). Hubungan Antara Knowledge Sharing Capability, Absorptive Capacity dan Mekanisme Formal. Jurnal Teknik Industri, 158-170.

Andria, Trisyulianti. (2011). Implementasi Manajemen Pengetahuan dan Dampaknya Terhadap Kinerja Organisasi. Jurnal Manajemen dan Organisasi, 155-171.

Anggapraja. (2016). Pengaruh Penerapan Knowledge Management dan Pengembangan SDM terhadap Kinerja Karyawan. Jurnal Aplikasi Manajemen (JAM), 14-17.

An-Ho, L. (2011). Mediation Learning Organizational Innovation and Performances. Journal Industrial Management \& Data, 113-131.

Athoilah. (2017). Model Peningkatan Knowledge Sharing Berbasis Modal Sosial dan Learning Organization terhadap Kinerja Agency. Jurnal Ekonomi dan Bisnis, 174-183.

Aulawi, Hilmi. (2009). Hubungan Knowledge Sharing Behavior dan Individual Innovation Capability. Jurnal Teknik Industri, 174-187.

Azadehdel, M. R. (2015). The Relationship Between Knowledge Sharing,Innovation and Performance. Interdisclipinary Journal Of Contemporary Research in Business, 403-412.

Bangun, W. (2012). Manajemen Sumber Daya Manusia. Jakarta: Erlangga.

Chuang. (2016). Can Knowledge-Intensive Teamwork Be Managed? Examining the Roles of HRM System,Leadhersip \& Tacit Knowledge. Journal of Management, 13-21.

Cinthya, L. (2018). Knowledge Sharing Sebagai Mediasi Pengaruh Learning Organization Terhadap Kinerja Karyawan. Jurnal Inspirasi Bisnis dan Manajemen, 79-90.

Fanbasten, N. (2014). Enhancing Bussines Performances Thourgh Learning Organization and Knowledge Sharing The Mediating Effect Innovation Capability Using PLS Method. Journal The Winners, 1-13.

Jo, J. (2011). Knowledge Sharing The Influences of Learning Organization Culture, Organizational Commitment and Organizational Citizenship Behaviors. Journal Of Leadhersip and Organizational Studies, 353-364.

Kuzu, O. (2014). The Effect of Employee Relationships and Knowledge Sharing on Employees Performance an Empirical Research On Service Industry. Journal Social and Behavioral Sciences, 1370-1374.

Lin, H. F. (2007). Knowledge Sharing and Firm Innovation Capability an Empirical Study. International Journal of Manpower, 315-332.

Lumbantobing, P. (2011). Manajemen Knowledge Sharing Berbasis Komunitas. Bandung: Knowledge Management Society Indonesia.

Makrufah. (2011). Pengaruh Budaya Pembelajaran Organisasi Terhadap Kinerja Karyawan Hotel Bumi Surabaya. Jurnal Akutansi Manajemen Bisnis dan Sektor Publik (JAMBSP). 
Mankunegara, A. P. (2011). Manajemen Sumber Daya Manusia. Bandung: PT Remaja Rosdakarya.

Marsicks, Watkins. (2015). Demonstrating the Value of an Organization Learning Culture The Dimensions Of the Learning Organization Questionare. Advances in Developing Human Resources, 132-151.

Mehmet. (2011). The Effect of Organizational Learning on Firm Innovation Capability: An Investigation in the Banking Sector. Global Business and Management Research An International Journal, 1-17.

Nawawi,Hadari. (2006). Evaluasi dan Manajemen Kinerja di Lingkungan Perusahaan dan Industri. Yogyakarta: Gadjah Mada University Press.

Novian, Yuniadi. (2018). Pengaruh Knowledge Sharing Terhadap Individual Innovation Capability. Jurnal Administrasi Bisnis (JAB) Universitas Brawijaya.

Noviyanti. (2015). Pengaruh Knowledge Management Terhadap Inovasi,Implementasi Strategi dan Kinerja Organisasi (Studi RS Lavette Malang). Jurnal Ekonomi dan Bisnis Universitas Brawijaya.

Nurwanti. (2013). Peran Pemimpin,Organisasi Pembelajar dan Kompetensi Organisasi Serta Dampaknya Terhadap Kinerja Organisasi. Jurnal Bisnis dan Akutansi, 177-136.

Obeidat,Abdallah. (2017). The Effect Of Intelectual Capital On Organization Performance The Mediating Role Of Knowledge Sharing. Communication and Network, 1-27.

Pedler, B. (2003). Learning Company. New York: Project Report Training Agency.

Rose,Kumar. (2015). The Effect Organizational Learning on Organizational Commitment,Job Statisfaction and Work Performances. The Journal Of Applied and Business Research, 55-66.

Setiarso, Bambang. (2017). Penerapan Knowledge Manajemen di Organisasi. Jakarta: Erlangga.

Suzete, A. (2016). Effects of Authentic Leadership, Affective Commitment and Job Resourcefulness on Employees' Creativity and Individual Performance. International Journal of Workplace Health Management, 1038-1055.

Tobing,Paul.(2007). Knowledge Management "Konsep,Arsitektur dan Implementasi". Yogyakarta: Graha IImu.

Ussawanitchakit. (2007). Innovation Capability and Export Performances an Empirical Studies Of Textile Business in Thailand. International Journal Business Strategy, 1-9.

Visvalinggam,Manjit. (2011). Organizational Culture Influence On Tacit Knowledge Sharing Behaviour. Journal Of Knowledge Management, 465-466.

Wahyuni Tri,Kristiyanto. (2013). Pengaruh Berbagi Pengetahuan Terhadap Kinerja Departemen Melalui Inovasi Jasa Pelayanan. Jurnal IImu Manajemen (JIM), 76-108.

Zaid, H. (2012). The Impact Of Job Statisfaction and Knowledge Sharing on Employee Performances . Journal Of Resources Development and Management, 22-24.

Zohoori,Mahmood. (2013). The Relationship Between Knowledge Sharing and Innovation in Electronic Industry Of Iran. Interdisclipinary 